\title{
Extraction of Dye from Detarium microcarpum and Its Application on Leather
}

\author{
Abubakar Sanusi \\ The Department of Pure and Applied Chemistry, Faculty of Science, Usmanu Danfodiyo University, Sokoto, Nigeria \\ Email address: \\ Asanusi013@gmail.com \\ To cite this article: \\ Abubakar Sanusi. Extraction of Dye from Detarium microcarpum and Its Application on Leather. American Journal of Polymer Science and \\ Technology. Vol. 6, No. 4, 2020, pp. 40-48. doi: 10.11648/j.ajpst.20200604.12
}

Received: November 16, 2020; Accepted: December 1, 2020; Published: December 31, 2020

\begin{abstract}
The present research is aimed at extraction of dye from the seed of Detarium microcarpum (taura). The dye was extracted by soxhlet extractor using ethanol as the solvent. The dye produced was analyzed for its solubility, $\mathrm{P}^{\mathrm{H}}$, functional group, and phytochemicals. The result of the solubility shows that the dye extracts have different solubility in different solvent medium as a result of the differences in composition of the solvent. From the FTIR result, the absorption band at $3302.4 \mathrm{~cm}^{-1}$ is due to the presence of $-\mathrm{OH}$ functional group from alcohol and $-\mathrm{NH}$ from amines, $1744.4 \mathrm{~cm}^{-1}$ is due to the presence of aldehydes and ketones which serves as auxochromes on the chromogen molecule responsible for the dyeing ability of the Detarium microcarpum extract. The phytochemical screening reveals the presence of phenol, quinines and Anthraquinones which are the secondary metabolites present in the seed of Detarium microcarpum. The dye extract can also be used to colour substances such as food, cotton, fabric, especially leather with a degree of performance as a result of the force or bonds formed between the dye molecules and the leather substrate. In the course of the soxlet extraction, it also revealed that the seed of Detarium microcarpum contained in it a bio-oil which was extracted alongside the dye. Result from FTIR revealed that the oil is also edible and consumable.
\end{abstract}

Keywords: Dye, Leather, Extraction

\section{Introduction and Literature Review}

\subsection{Introduction}

Dyes can generally be described as colored substances that have affinity to the substrates to which they are being applied [27]. Dyes are soluble and go through an application process which, at least temporarily, destroys any crystal structure by absorption, solution, and mechanical retention, or by ionic or covalent chemical bonds [24].

The craft of dyeing is severally thousand years old. It was believed that dyeing was practiced as early as 3000 BC. In Egypt, the Egyptians were making textile mats which they hung on their walls by about 1450 BC. The Egyptians were making textile materials of astonishingly delicate structure and were able to dye them in a whole range of different colors. The earliest records of Indian religious and social practices at about $2500 \mathrm{BC}$ were found to consist of colored silk and gold from them already, an established practice. [25]

Until the middle of $18^{\text {th }}$ century, all dyes were obtained from natural source. The dyes mainly used then were those obtained from the madder and indigo plant, and they are of the mordant class. They require the use of mordant during application. A mordant is a substance usually a metallic compound applied to a substrate to form a complex with a dye which is retained by the substrate more firmly than the dye itself. [6]

Potash alum, which is the double sulfate of potassium and aluminum, is the most widely used aluminum mordant for natural dyeing. It can be used alone or with cream of tartar or as basic alum for mordanting. When used alone, the material before dyeing is merely boiled in a solution of alum. The amount of mordant required depends on the shade to be dyed. If deeper shades are being dyed, more mordant is needed. Generally $10-20 \%$ of alum can be used on the weight of the material. If used along with cream of tartar, alum powder $(20 \%)$ is mixed with the cream of tartar $(40 \%)$ in a little warm water and diluted to the required volume. Alum in the form of basic aluminum sulfate (neutral alum) is used as a mordant for cotton. It is prepared by adding sodium hydroxide or carbonate solution to the aqueous solution of 
alum till the precipitate formed dissolves upon stirring. The material to be treated is dipped in the alum solution and the latter is then fixed by other chemicals or ageing. It is preferable to fix the alumina on the fiber by precipitating it with salts such as sodium carbonate or sodium phosphate to obtain good dyeing results. Neutral soap solution can also be used. [28] in another method suggest that the material is dipped in vegetable tannins/tannic acid or oil mordant such as Turkey red oil before treatment with basic alum which results in good fixation of aluminum. Other aluminum salts such as aluminum sulfate or acetate can also be used for mordanting [6]

Both dyes and pigments appear to be colored because they absorb some wavelength of light more than others. In contrast with a dye, a pigment generally is insoluble and also has no affinity for substrate. With the development of synthetic dyes, basic and acid dyes which require no mordant become available enable dyeing of leather to unknowing brightness to be produced. [6]

The first synthetic dye was synthesized by Perkin in 1856 and 1869. Grabe and Lieberman synthesized Alizarin, other closely related dye are Anthracene brown and Alizarin orange [25]

Unlike most organic compounds, dyes posses color because they absorb light in the visible spectrum (400$700 \mathrm{~nm}$ ), have at least one chromophore (color-bearing group) which has a conjugated system, i.e. a structure with alternating double and single bonds, and exhibiting resonance of electrons, e.g benzene $\left(\mathrm{C}_{6} \mathrm{H}_{6}\right)$ which is a stabilizing force in organic compounds [25]. When any one of these features is lacking from the molecular structure the color is lost. In addition to chromophores, most dyes also contain groups known as auxochromes (color helpers), examples of which are carboxylic acids (-COOH), sulfonic acid, amino $(\mathrm{NH})$ and hydroxyl groups $(\mathrm{OH})$. While these are not responsible for color, their presence can shift the color of a colorant and they are most often used to influence dye solubility. Examples of chromophoric groups present in organic dyes include Anthraquinone, methane, Phthalocyanine, Triarylmethane etc. [8].

In addition to influencing solubility, auxochromes are essential ring substituent's improving target colors, where the following effects of substituent are shown:

1. Adding groups of increasing-donating ability to the azobenzene structure has a bathochromic effect $(\mathrm{OH} v s$ $\mathrm{NH}_{2}$ )

2. Electron-donating $\left(\mathrm{NH}_{2}\right)$ and electron-accepting $\left(\mathrm{NO}_{2}\right)$ groups placed in conjugation provide a bathochromic effect. In this regard, nitro groups are especially beneficial, contributing to their prevalence in disperse dye structures.

3. Increasing the number of electron-attracting groups conjugated with the electron-donor has a bathochromic effect.

4. The electron-donating effects of an amino group are enhanced by adding alkyl groups to the $\mathrm{N}$-atom.

\subsubsection{Potential Sources of Natural Dyes}

Natural dyes are derived from natural resources and base upon their sources of origin, these are broadly classified as plant, animal, mineral and microbial dyes. Although plants are the measure sources of natural dyes. [28]

Natural dyes comprised of those colors derived from plants or insects without chemical processing e.g. log of wood, fustic, roots, leaves, and cochineal. They are been known and used for thousands of years without any report showing that they are harmful, modern test which have verified the safety of natural dyes as food colorants like the color of drugs, cosmetics and medical devices. The operation involve in processing natural dyes for market are purely physical such as grinding, water or solvent extraction and spray or vacuum drying. Besides their coloring ability they have some tanning potency which can be used as an advantage because they further tan the skin giving fuller and softer leather. Demands safer textile products especially for babies and children as reported in EU needs for quality products [10]. The usage and production of natural dyes from plants sources has become better known due to growing awareness of the environment and health care [26].

Coloring components are derived from roots, barks, leaves, fruits and flowers of plant sources. However, the dye yield and pure dye content in dye plant is usually quite low compared to synthetic dyes [23, 17] reported that the three old madder plants gave root yield about 4.8 tons per hectare with dye yield of $37.7 \mathrm{~kg}$ per hectare, only with pure dye content of $2.3-4.4 \%$ of the total weight of the dried root [17] The pictorial strength (weight needed to produce a color of required depth on fiber) also needs to be considered. About $1.5 \mathrm{~g}$ of a synthetic dye is required to dye $100 \mathrm{~g}$ of fiber in medium depth of shade, whereas; about 120-240 $\mathrm{g}$ of dry plant dye which may be equivalent to 500-1000 g of fresh dye plant source would be required to achieve the same result. The amount of fresh plant material needed to replace synthetic dye with natural dyes for dyeing the annual production of cotton and wool is estimated to be 191 million tons. These relationships have important implications for the production of dye crops when the replacement of synthetic dyes with natural dyes is taken into consideration. [8]

Synthetic dyes are those compounds derived from chemical organic compound and one of the early and important materials used in these syntheses was aniline derived from coal tar. The manufacturing of these dye proceed from sample raw material mostly aromatic hydrocarbon which is benzene (Benzol), and naphthalene with the introduction of other chemical groups such as nitro, amino, halogen and sulfonic acid.[5]

These intermediate compounds are then further processed by many special operations in organic chemistry such as Diazotization, coupling, condensation and fusion to give the final dyestuff. [8]

\subsubsection{Some Important Dyes Are Listed Below}

Natural dyes have a complex chemical constitution. Unlike synthetic dyes, they are usually not a single entity but a mixture of closely related chemical compounds. 
On the basis of major chemical constituents present, they are divided into:

1. Indigoid dyes

2. Anthraquinone dyes

3. Naphthoquinone dyes

4. Flavonoid dyes

5. Carotenoid dyes

6. Tannin-based dyes

Anthraquinone dye is a large number of natural dyes especially red color-producing dyes fall into this category. The most famous natural dye in this category is alizarin obtained from European madder (Rubiatinctorum). Other dyes include lacs, cochineal, morinda and Indian madder (manjishth/manjeet) among others. [8]

Naphthoquinone dyes: some of the natural dyes belonging to this category are henna, walnut shells, and so on. The coloring matter of henna is laws one which is 2-hydroxy naphthoquinone and walnut shells contain jug lone like anthraquinone dyes. [8]

Flavonoid dyes: most of the yellow natural dyes have a hydroxyl or methoxy substituted flavones structure. Dyes with this chemical constitution are found in a wide variety of natural resources. Weld (Reseda luteola) or dyer's rocket was widely used in Europe to produced fast and brilliant colors on wool and silk. [8]

\subsection{Literature Review}

\subsubsection{Description of Deterium Microcarpum}

Detarium microcarpum belongs to the family Fabaceae. It is found mostly in the Savannah forest. The tree is called 'Taura' (Hausa), 'Ofo' (Igbo), Ogbogo (Yoruba) and 'Agalyem' (Tiv) [12]

It is multipurpose specie with a wide range of use due to its medicinal properties, edible fruit (eaten raw, cooked, or made into flour) and hardwood used as fuel-wood. [1]

D. microcarpumoccurs naturally in the drier legumes of West and Central Africa (Benin, Cameroon, Central Africa Republic, Chad, Gambia, and Guinea Bissau, Cote d Ivoir, Mali, Nigeria, Senegal, Sudan and Togo). Unlike the other species of its family, D. microcarpum grows in dry savannah while the Detarium Senegalese grows in dry forest and Detarium microcarpum grows in humid forest, and many different vascular names exist for this species, the English sweet dattock or tallow tree and the French Dankh or petit defar as well as abu-laili (in Sudan) or tambadala (in Mali) taura and kwakuragwahiu in Hausa and Kilba in northern Nigeria. [20].

\subsubsection{Taxonomical Classification}

$\begin{array}{ll}\text { Kingdom } & \text { Plantae } \\ \text { Family } & \text { Fabaceae (Leguminosae) } \\ \text { Subdivision } & \text { Caesalpinoidae } \\ \text { Tribe } & \text { Datarieae } \\ \text { Sub-family } & \text { Swietenoideae, tribe Swietenieae } \\ {[1]} & \\ \text { Synonyms } & \text { detariumsenegalenseGamel } \\ \text { Genus } & \text { D. senegalense and D. macrocarpum [20] }\end{array}$

\subsubsection{Botanical Description}

The tree grows to a height of about $10 \mathrm{~m}$, usually with twisted trunk and branches. Leafletsare2-5pairs, palegreen, elliptic apex sometimes retuse, base oblique. The flowers are white, fragrant in dense panicles. The flowers are sub sessile with four sepals and no petals. The orbicular fruit $(3.175 \mathrm{~cm}$ in diameter) is dark brown and it is brittle when dry and is sweet and edible. [14] The tree is wide-spread in Tropical West Africa in dry Savannah habitat having twisted trunk and wide spreading crooked branches, bark is slate grey, rough, producing regular flakes, reddish beneath, slash hard and reddish, bark of branch-lets are orange colored, smooth or peeling off in papery patches [19].

Leaves are compound, pinnate; leaflets are alternate or sub opposite, rounded both basalt and at apex, 2-6 pairs and hairy, each leaflet is $11 \mathrm{~cm}$ long and $4 \mathrm{~cm}$ broad with numerous translucent point [20].

Inflorescence occurs in panicles, congested, arising slightly from leaf axils or usually in clusters, flower are white, fragrant and stalked, whole inflorescence hairy fruit is a drupe, more or less circular and disc-like shape $5 \mathrm{~cm}$ in diameter. The dry fruit is dark brown, smooth; enclosing a sweet, a greenish pulp entangled in a mesh of fibers surrounding a disc-shape wrinkled stone containing one or two seeds. Flowers are produced throughout the wet season. Fruits occur in November, January and May [1].

Deuterium microcarpum is an African tree belonging to the fabaceae family (legume), it is a small tree or shrub growing up to $15 \mathrm{~m}$ tall but can reach $25 \mathrm{~m}$ on moist in terms of growth rate. The shoots of the trunk can reach a height of $1.5 \mathrm{~m}-2 \mathrm{~m}$ in one or two years and are much more vigorous than seedling which an average growth of $0.6 \mathrm{~m}$ after three years and may reach $1.5 \mathrm{~m}$ in four years, it flowers during the rainy season (July to September/November), but the main flowering tree sheds its leaves and produces new leaves in March. [3]

\subsubsection{Habitat}

Propagation of these species may be vegetative or from seed. It is capable of vegetative propagation by coppice and suckering from stumps or roots as well as propagation by rooted cottons and grafting using scions from shallow strong and lateritic soil often on hill as in region with annual rainfall of $600-1000 \mathrm{~mm}$. it is mostly common in wooded savannah semi cleared dry forest area and follow growing in sandy or hard soil with high iron content [3].

\subsubsection{Medicinal Uses}

The use of herbal medicine may be as old as the history of mankind. [1] have reported that the use of plant as medicine is an ancient practice present to all society especially African societies of which the Kilba community of Hong Local government of Adamawa state is not left out in the use of Deterium microcarpum [7].

The medicinal values of the tree are:-The bark is haemostatic and is used to heal deep cut. In Liberia, the bark decoction is used in parturition, and has quick effect in cases of retained placenta. A cold infusion of the bark, root and 
wood is used in Senegal as restorative for weakness and anaemia. [18] The fruit is used as balm for chronic backache or tuber culosis of the spine. The fruit is a remedy for chest diseases in parts of West Africa [12] In Northern Nigeria, the fruit $\mathrm{s}$ with other fruits are used as a toxin and as stimulant on a journey. The young soft seeds are usually given to people wounded by poisoned arrow [19].

The plant is useful in curing diseases other diseases such as, venereal disease, urogenial infection, stomach ache, intestinal worms and diarrhea including dysentery. The fresh bark or leaves are applied to wounds to prevent and cure infection. [20] Despite the numerous medicinal application of this herbal plant phytochemical analysis on it are scarce and thus deserve more attention [2].

Medicinal properties in the roots, stem leaves and fruits show inhibitory effect on HIV-1 or HIV-2 infection. In methanol extracts, the leaves and roots are also used to treat farm animals and also used against malaria and impotence because of its astringency [3].

The search for new antimicrobial agents from plant source is an important line of research because of the resistance acquired by several pathogenic micro-organisms [9] The phytochemical screening of various crude extract of D. Microcarpum reveals high and moderate concentration of terpenoid, cardiac glycosides, tannins flavonoids and carbohydrate. Some of which compound especially flavonoids, tannins, cardiac glycosides and terpenoids have been reported to have anti-microbial and curative properties. $[17,11]$

The presence of these bioactive plant constituents in all the extract of D. microcarpum and their anti-bacterial/antimicrobial and curative properties against pathogenic microorganisms will give credibility and basis for the wide use of these plants in the folk low medicine as treatment for the infant ailment gedigedi or tando and wound healing properties and host of other medicinal uses of the plants as reported by [8],[20] and other oral reports of the plant from its distribution areas.

Its hard brown wood provides very good quality which is very durable under water and used in carpentry and concentration use for firewood and charcoal. The root, stem, bark, fruits and leaves all used to treat ailment e.g. tuberculosis, meningitis, itching and diarrhea. The fruit is edible and rich in vitamin $\mathrm{C}$. the seeds are used in cooking and foliage is avoided by most large mammals whereby the roots are used in perfume [4].

\section{Used As Food}

The fruit is edible. A sweet meal is sometimes prepared from it together with the fruits of Vitexdoniana and Diospyrosmespiliformis [19]. What the Hausas called 'madi' it is a common believe by the Hausa people that too much eating of the fruit causes vertigo (i.e. feeling of dizziness, fear and loss of balance). On the other hand, the small absorption fruit of quite different shape probably galls are produced by the tree are poisonous to persons who may inadvertently eat them when hungry [1] reported that, the kernels of the seeds are deep purple brown and are oily and edible. The Nupe people bake the seeds into cake as foodstuff for cattle. The seed are used accented necklace sand waist girdles. The burning of the seeds drive away mosquitoes; while the ash is employed in the preparation of snuff by the Liberians [19].

D. Microcarpum has several other uses for rural communities leave being used root seed dried and made into necklaces or are grind and used as a fragrance and mosquito repellent prepared from roots. [1, 20]

The D. Microcarpum fruit is rich in vitamin C $(3.2 \mathrm{mg})$ with $4.8 \mathrm{~g}$ of protein and $64.5 \%$ sugar. It was found to have the highest total polyphenolic, flavonoid and antioxidant value among fourteen with edible fruits from Burkina Faso. The fruit pulp has been found to have high proportion of carbohydrates $40-42 \%$ and protein $29.1-30.9 \%$. The seed yield $7.5 \%$ oil with the predominantly fatty acid being linotec acid. The hulled seed flour contains per $100 \mathrm{~g}, 3.5-3.6 \mathrm{~g}$ water, $3 \mathrm{~g}$ crude fiber, $13.15 \mathrm{~g}$ crude fats, $13.5-27 \mathrm{~g}$ crude protein, $39 \mathrm{~g}$ carbohydrate, $500 \mathrm{mg}$ of calcium, 500mg of magnesium, and $100 \mathrm{mg}$ of iron. [9, 15]

\subsubsection{Advantages of Natural Dyes}

Natural dyes are considered to be eco-friendly as these obtained from the renewable resources are compared to synthetic dyes which are derived from non-renewable petroleum resources. In addition to these environmental benefits natural dyes also offer functional benefits to the wearing and users of such textiles. [28] Some advantages of natural dyes include:

Minimal environmental Impact: Because they come from natural sources, natural dyes are not harmful to the environment, which makes it so appealing for consumers. Natural dyes are biodegradable and disposing them doesn't cause pollution.

Renewable: Natural dyes are obtained from renewable sources that can be harnessed without imposing harm to the environment.

Colour pay-off: If you are going for a soft hue or soothing shade, natural dyes an help you achieve that look.

Safe: Some natural dyes, such as carmine found in lipsticks, will not cause harm or health problems when ingested.

\subsubsection{Disadvantages of Natural Dyes}

Natural dyes are considered to be an eco-friendly alternative for dyeing textile materials, especially natural fiber and textiles. However there are many limitations in the usage of natural dyes. Some of which are listed below:

Cost: A larger amount of natural dyes may be needed in order to dye a specific amount of fabric as opposed to synthetic dyes. for instance, one pound of cotton may be dyed with just five grams of synthetic dye, whereas 230 grams of natural dyes are needed to dye the same amount of material. Since that is the case, using natural dyes is more expensive than synthetic dyes. [28]

Color pay-off: Color pay-off from natural dyes tend to fade quickly. More so, quality may not be as consistent as what synthetic dyes can deliver. [28]

Availability: Another issue with natural dyes is their availability. It can be difficult to produce because the 
availability of raw materials can vary from season to season, place and species, whereas synthetic dyes can be produced in laboratories all year round. [28]

Harmful Effects: Natural dyes can also be harmful to some extent. Logwood has ingredients, hematein and hematoxylin, that can have some harmful effects when inhaled, ingested, or absorbed through the skin. Brood root, another natural dye source, can cause irritation and inflammation when inhaled. More so, natural dyes may need mordants for application. While these substances help the dye stick to fabrics, they can also be toxic. Examples of mordants used in natural dyes are aluminum, copper, iron and chrome. [28]

Sustainability: While natural dye sources are renewable, sustainability can still be an issue for natural dyes because producing them require vast areas of liquid. [28]

\subsection{Research Problem}

Since colors have become the most important part of every community, the chemistry of natural colors can fail to fascinate synthetic colors. Synthetic colorant tends to impart undesirable test in food and harmful to human being, as these are responsible for allergenic and intolerance reaction. Customers prefer natural color mainly because they are healthy and have good qualities as a result of this; the color from deuterium microcarpum seed will be investigated.

\subsection{Justification}

The identified problems associated with the use of synthetic dye have encouraged the research for low cost dye especially of biological origin that will be effective easy to use and safe to both the human and environment health. Natural dye can easily be prepared at home. It has less side effect unlike the synthetic dye due to which there maybe hair-fall, rashes, itching and the idea of using natural dye are pleasant because it reduce the cost of procuring synthetic dye, create employment and in addition to increase the domestic need and foreign exchange saving to the country by substituting the current importation of dyes.

\subsection{Scope and Limitation}

This work is limited to extraction of dye from Deteriummicrocarpum seed (taura) and its application on leather as a dye. The dye extract produced has low yield due. This however is due toimpurities attached to the solvent used.

\subsection{Aim and Objectives}

\subsubsection{Aim}

The aim of this research work is to extract dye and produce a natural dye from the seed of Detariummicrocarpum plant.

\subsubsection{Objectives}

The specific objectives include:

1. To extract dye from Detariummicrocarpum seed.

2. To examine the potential impact of the dye on the substrate (leather).

3. To carry out physicochemical analysis of the type of organic dyeconstituent present.

4. To characterize the dye using FTIR.

\section{Materials and Method}

\subsection{Materials}

\subsubsection{Apparatus}

The apparatus, instruments and chemicals used in this experiment are presented below:

Table 1. List of Apparatus.

\begin{tabular}{lll}
\hline Apparatus & Model & Manufacturer \\
\hline Measuring cylinder & Glass & Pyrex, England \\
Conical flask & Glass & Pyrex, England \\
Beaker & Glass & Pyrex, England \\
Volumetric flask & Glass & Pyrex, England \\
Test tube & Glass & Pyrex, England \\
Mortar and pestle & Ceramics & Ohaus, China \\
Filter paper & Glass & Pyrex, England \\
Pipette & Glass & Pyrex, England \\
Evaporating dish & Glass & Pyrex, England \\
Funnel & Glass & England \\
\hline
\end{tabular}

\subsubsection{Instruments}

Table 2. List of instruments.

\begin{tabular}{lll}
\hline Instrument & Model & Manufacturers \\
\hline $\begin{array}{l}\text { Soxhlet apparatus } \\
\text { FTIR }\end{array}$ & 4500 & Asian test Equipments Ghaziabad \\
$\begin{array}{l}\text { Electric weighing } \\
\text { balance }\end{array}$ & AIM-9000 & Shimadzu Cooperation \\
Oven & DT 100 & Galen UK \\
Water bath & SD900 & ACCRO-TECH Scientific Indu, \\
& LE101-102 & GPC Delhi, India. \\
\hline
\end{tabular}

\subsubsection{Reagents}

Table 3. List of reagents.

\begin{tabular}{|c|c|c|}
\hline Name & Formula & $\%$ Purity \\
\hline Conc. Sulfuric acid & $\mathrm{H}_{2} \mathrm{SO}_{4}$ & 98 \\
\hline Conc. Hydrochloric acid & $\mathrm{HCl}$ & 36.5 \\
\hline Acetic acid & $\mathrm{CH}_{3} \mathrm{COOH}$ & 99.5 \\
\hline Nitric acid & $\mathrm{HNO}_{3}$ & 95.5 \\
\hline Ammonia solution & $\mathrm{NH}_{4} \mathrm{OH}$ & 99 \\
\hline Ferric chloride & $\mathrm{FeCl}_{3}$ & 96 \\
\hline Distilled water & $\mathrm{H}_{2} \mathrm{O}$ & 100 \\
\hline Sodium hydroxide & $\mathrm{NaOH}$ & 98 \\
\hline Sodium chloride & $\mathrm{NaCl}$ & 96 \\
\hline Chloroform & $\mathrm{CH}_{3} \mathrm{Cl}$ & 96 \\
\hline Ethanol & $\mathrm{CH}_{3} \mathrm{OH}$ & 98 \\
\hline
\end{tabular}

\subsection{Methods}

\subsubsection{Sample Collection}

Detariummicrocarpum (taura) fruit was obtained from Funtua and samaru-zaria markets of Katsina and Kaduna state respectively. It was identified as detariummacrocarpum, belonging to fabaceaefamily, with identification number of 169 in UsmanDanfodio University Sokoto state Nigeria.

\subsubsection{Sample Preparation}

The obtained Detariummicrocarpum fruit was sun-dried, 
broken for its seed using mortar and pestle and hair-dried. The seeds were crushed to powder form using grinding machine. The powdered sample was weighed and stored in polythene bag.

\subsubsection{Solvent Extraction Procedure}

The extraction of dye from detariummicrocarpum seed was carried out using soxhlet extraction method, where by $50 \mathrm{~g}$ of grinded sample was weighed and transferred in to thimble chamber of the apparatus using $250 \mathrm{ml}$ of ethanol, the soxhlet apparatus extraction was carried out base on solid liquid extraction a basic type of extraction. The sample was place in the porous thimble and inserted into the inner tube, the extractor was then fitted to the bolt head flask containing the solvent on the flux condenser. The solvent boiled gently at $60^{\circ} \mathrm{C}$ as the vapour pass through the tube while the condensed solvent falls back into the siphoning point. It siphoned slowly and filled the body of the soxhlet. When the solvent reach the siphoning point, it siphoned over the flask and thus removed that portion of the substances which it has extracted. The process was repeated until the complete extraction was effected. The extracted compound was isolated from its solution through the use of calibrated evaporating dish and bath, and the process last for $3 \mathrm{hrs} 45 \mathrm{mins}$.

\subsubsection{Fourier Transform-Infrared Studies}

Functional group were identified by the crude dye extract, major peaks were identified for different type of $\mathrm{C}=\mathrm{C}, \mathrm{C}-\mathrm{H}$, $\mathrm{C}=\mathrm{O}$, O-H stretching and bending vibration. Absorption in the infrared region is due to molecular vibration of one kind or another, the spectrum is generally very complicated and contains many absorption peaks. [2]

\subsubsection{Phytochemical Screening}

A qualitative screening was carried out to detect the presence of phytochemicals in plant extracts. Flavonoid quinines, Cuomones, Anthraquinones and Carotenoids were the chemical compound practically relevance. The phytochemical tests were performed on the liquid extract using standard method. [2]

Table 4. Phytochemical Screening Protocols.

\begin{tabular}{|c|c|c|}
\hline Phytochemcals & Test & Color \\
\hline Phenol & $1 \mathrm{ml}$ of extract $+2 \mathrm{ml}$ distill water $+10 \% \mathrm{Fecl}_{3}$ & Blue or green \\
\hline Anthocyanin & Extract + conc. $\mathrm{H}_{2} \mathrm{SO}_{4}$ & Yellowish orange \\
\hline Quinines & $1 \mathrm{ml}$ of extract $+1 \mathrm{ml}$ of $\mathrm{H}_{2} \mathrm{SO}_{4}$ & Red \\
\hline Cuomorines & $1 \mathrm{ml}$ of $10 \% \mathrm{NaOH}+1 \mathrm{ml}$ extract & Yellow color \\
\hline Anthraquinones & $1 \mathrm{ml}$ of extract + few drops of $10 \% \mathrm{NH}_{3}$ & Pink colorppt \\
\hline Flavonoids & $1 \mathrm{ml}$ of extract + drops of $\mathrm{NaOH}+$ drops of dilute $\mathrm{HCl}$ & Colorless appearance \\
\hline Carotenoids & Extract + chloroform + drops of $\mathrm{H}_{2} \mathrm{SO}_{4}$ & Deep blue coloured \\
\hline
\end{tabular}

\subsubsection{Solubility Test}

The dye extract was dissolved in different media respectively, to test for its solubility $1 \mathrm{~g}$ of the sample extract was placed in five different test tubes and $5 \mathrm{ml}$ of each of the following solvent; distilled water, sodium hydroxide, hydrochloric acid, and ethanol respectively and shaken for 10 minutes. [3]

\subsubsection{Mordanting of Chrome Tanned Leather}

$2 \mathrm{~g}$ of Aluminum sulphate were used for pre mordanting, the mordant were dissolved in water to obtain a solution. The leather was then dipped into the mordanting solution at $80^{\circ} \mathrm{C}$ for $5 \mathrm{mins}$ with constant stirring. The sample was dried under shade before immersing into the dye bath. [26]

\subsubsection{Dyeing of Mordant Leather with Dye Extract}

$1 \mathrm{~g}$ of dye extract was weighed and dissolved in $2 \mathrm{~cm}^{3}$ of ethanol and was dispersed in water already containing mordanted chrome leather, run for an hour at temperature of $45^{\circ} \mathrm{C}$ then fatliquor with $4 \%$ fat oil. The dye was fixed by adding
$0.5 \%$ formic acid diluting ratio 1:5 run for 40 minutes. The unfixed dye was wash off and rinsed [26, 29].

\section{Results and Discussion}

\subsection{Results}

Based on the methods used for the analysis and characterization of the dye extract of detariummicrocarpum the following results were obtained:

Table 5 shows the result of the solubility of the dye extract in different solvents.

Table 5. Result of solubility test.

\begin{tabular}{ll}
\hline Sample + solvent & Observation \\
\hline Extract + distilled water & Partially soluble \\
Extract $+\mathrm{NaOH}$ & Soluble \\
extract + conc. $\mathrm{HCl}$ & Insoluble \\
Extract + conc. $\mathrm{H}_{2} \mathrm{SO}_{4}$ & Soluble \\
Extract + ethanol & Soluble \\
\hline
\end{tabular}

Table 6. Result of phytochemical screening.

\begin{tabular}{|c|c|c|c|c|c|c|c|c|c|c|}
\hline $\mathbf{S} / \mathbf{N}$ & Phytochemicals & Green & Blue & Yellow & Red & Pinkppt & IntenseYellow & ColorlessAppearance & Deep blueLayers & Yellow orange \\
\hline 1 & Phenol & ++ & ++ & - & - & - & - & - & - & - \\
\hline 2 & Anthocyanin & + & + & - & - & - & - & - & - & - \\
\hline 3 & Quinones & - & - & - & + & - & - & - & - & - \\
\hline 4 & Cuomarine & - & - & - & - & - & - & - & - & - \\
\hline 5 & Anthraquinones & - & - & - & - & ++ & - & - & - & - \\
\hline 6 & Flavonoids & + & + & - & - & - & - & - & - & \\
\hline
\end{tabular}


Table 7. Result of FTIR.

\begin{tabular}{ll}
\hline Frequency $\left(\mathbf{c m}^{-1}\right)$ & Functional group \\
\hline 3302.4 & -OH stretch (alcohol), $-\mathrm{NH}$ stretch (amines or amides \\
2922.2 & stretch) \\
1744.4 & $-\mathrm{CH}$ stretch (alkanes) \\
1602.8 & $-\mathrm{C}=\mathrm{C}$ stretch (alkenes), $\mathrm{C}=\mathrm{O}$ stretch (aldehydes or ketones) \\
\hline
\end{tabular}

\subsection{Discussion}

The result of the solubility shows that the dye extracts have different solubility in different solvents medium as a result of the differences in composition of the solvent.

The $\mathrm{pH}$ of the aqueous extract (crude) was determined to be 5.5 .

The infrared spectroscopy of the ethanol extracts functional groups absorption bonds are shown in Table 7 .

Depicts the various wavelengths of the aqueous extract the peak observed at $3302.4 \mathrm{~cm}-1$ is attributed to $-\mathrm{OH}$ from alcohol and $-\mathrm{NH}$ stretch from Amines. The absorption band at $2922.2 \mathrm{~cm}-1$ is due to $\mathrm{C}-\mathrm{H}$ stretch typically from alkanes, the absorption band at $1744.4 \mathrm{~cm}-1$ is attributed to $-\mathrm{C}=\mathrm{C}$ stretch from alkenes, $-\mathrm{C}=\mathrm{O}$ stretch from aldehydes and ketones, and $1602.8 \mathrm{~cm}-1$ is due to $-\mathrm{C}=\mathrm{C}$ in the alkene. The absorption between1400-600 is not recorded as it falls under the finger print region. From the spectra it can be observed that the peaks increase in the extract is due to the presence of $-\mathrm{C}=\mathrm{O}$ from amide and aldehyde. [28] reported in "Chemistry of dyes and their application" that alcohol $(-\mathrm{OH})$ is the major functional group of majority of the dye extract.

Therefore the presence of $-\mathrm{OH}$ functional group from alcohol, $-\mathrm{C}=\mathrm{O}$ from aldehyde and $-\mathrm{NH}$ from amines, which serves as auxochromes on the chromogen molecule are responsible for the dyeing ability of the Detarium microcarpum extract. [21]

In table 6 shows the phytochemicals present in the dye extract, where phenol, quinones and anthraquinones are the secondary metabolites present in the seed of Detariummicrocarpum. [28] Also reported the presence of phenol, anthraquinones and flavanoids in the phytochemical evaluation of PsidiumGuajava leaf. Also [26] reported that natural dyes from plants are classified on the basis of major chemical constituent, and in plant phytochemicals are naturally present. They give colors, flavor, smell and texture from which a part of the phytochemicals could prevent disease such as cancer and cardiovascular. [13]

Hassan et al. reported that almost all the red natural dyes are based on the anthraquinoid structure having both plant and mineral origin [17]. Madder, lacks, kernes, cochineal are some of the dyes that posses this type of structure, these are generally mordant dye. The percentage yield of the extract for every $50 \mathrm{~g}$ of the sample was obtained to be $12.73 \%$ but according to [26] whom reported that natural dyes from plant have low yielding point. It is possible to take much of the plant materials and extract because the colorant is only $2-5 \%$ but to yield 1 gram of dye it's required approximately 100 grams of plant material [16].

\section{Conclusion and Recommendations}

\subsection{Conclusion}

A dye was produced from the seed of detariummicrocarpum (taura). The dye produced was analyzed for its solubility, $\mathrm{p}^{\mathrm{H}}$, functional group, and phytochemicals. It comprises chromophore and auxochrome from the result of the study especially the infrared spectroscopy. Analysis shows that naturally occurring colouring matter from plant such as detarium miccrocarpum can also be used to colour substances such as food, cotton, fabric, especially leather with a degree of performance which will also have good fastness to light and rub, as a result of the force or bonds formed between the dye molecules and the leather substrate.

\subsection{Recommendations}

From the result of the analysis, the following recommendations are proposed:

1. The seed of Detarium microcarpum can be recommended as an alternative source natural anthraquinone dye a source of raw oil which can be used as fat liquor in lubricating leather.

2. The dye extracted is edible and as such could be used in dyeing food materials such as rice.

\section{Appendices}

\section{Appendix 1. Percentage Yield}

Table 8. Yield of the dye extract from every $50 \mathrm{~g}$ of powdered taura seed.

\begin{tabular}{llll}
\hline Sample & mass of sample & mass of dye extract & \%yield \\
\hline Sample A & $50.00 \mathrm{~g}$ & $6.50 \mathrm{~g}$ & 13 \\
Sample B & $50.00 \mathrm{~g}$ & $5.20 \mathrm{~g}$ & 10.4 \\
Sample C & $50.00 \mathrm{~g}$ & $7.40 \mathrm{~g}$ & 14.8 \\
\hline
\end{tabular}

Appendix 2. Calculation of Percentage Yield of the Dye Extract

$$
\text { Percentage yield }=\frac{\text { Massofextract } \times 100}{\text { Massofpowderedsample }}
$$

For sample A

$$
\% \text { yield of the extract }=\frac{6.50 \times 100}{50}=13 \%
$$

For sample B

$$
\% \text { yield of the extract }=\frac{5.20 \times 100}{50}=10.4 \%
$$

For sample C

$$
\% \text { yield of the extract }=\frac{7.40 \times 100}{50}=14.8 \%
$$

Average of the three samples $=13+10.4+14.8 / 3=12.73 \%$ 


\section{Dedication}

I dedicate this project work whole heartedly to the Lord of the Heavens and the Earth, Allah (SWT).

\section{Acknowledgements}

In the name of Allah, the Most Gracious, Most Merciful. All praise and salutation be to Allah (SWT) the Lord and Nourisher of the Universe, who teaches man what He knew not.

I am particularly grateful to Almighty Allah (SWT) for the wisdom and guidance during the course of this research. I wish to gratefully acknowledged and express my sincere gratitude to my able and hard working Supervisor, Engr. I. I Rikoto whom in spite his tight schedules was able to offer his time, words of encouragement, constructive criticism which led to the overall success of the research. I will always be indebted to all the staff of the Department of Pure and Applied Chemistry for all the efforts they made during my academic period. Also my appreciation goes to Malam Aminu laboratory technologist Nigeria Institute of Leather and science technology Zaria and Mr. Bitrus Abila for their assistance and making their facilities available throughout the period of my practical research work.

My sincere gratitude goes to my parents Alh. Sanusi Yahaya and Haj. Fatima Binta Isa, for their moral and financial support, whom despite their personal problems took the pain of seeing me throughout my studies, In them I found the fulfillment of true parents and to them I owe the excellence appreciation and regards for their great kindness and hospitality, and to my grandparents whom I never knew, Mal. Yahaya Zakariyya and Malama Zainab whom did not survive to see the heir of the family.

Also I wish to express my appreciation to all my family members especially my well wishers Ibrahim Mansur and Ibrahim Tanimu, my sincere gratitude goes to aunty Hauwa'u Zakariyya and my uncle Alh. Auwal Idris, also to my mothers Haj. Mariya Shuaibu and Huraira Abubakar for their prayers and encouragements.

My sincere and profound gratitude goes to my elder sister Maryam Sanusi whom I consider like a mother and a close friend, when things go tough and higher to me she always have the solution, also to my elder brother Zakariyya Sanusi and to my indomitable sister, a childhood friend and friend forever Khadijah Sanusi, followed by Zainab Sanusi, Ummusalma Sanusi, Umar Sanusi and AliyuS anusi.

My words of appreciation goes to all my friends both at home and in school whose friendship, support and encouragement gave me serious inspiration all along my duration of course. They include Nuhu Sani Doki, Aisha Abubakar Tetu, Imrana Aliyu Shinkafi, Usman Abubakar Fanah, Muhammad Usman Rawayya and Salihu Aliyu (Dan Maliki) who have been assisting me throughout my research work, and to my very good friend, who form a very important part of my story, a sister from another mother whom I never regret being in her company Fatima Yusuf
Maiyama (Bodido) for her encouragement and advice.

\section{References}

[1] Abdulbasit A, Mohamed E. S. M, Ahmad B. U (2009). DetariummicrocarpumGuill and Perr fruit proximate chemical analysis and sensory characteristics of concentrated juice and jam. Afr J. Biotechnol. 8 (17): Pp 4217-4221.

[2] Abdullahi S. A, Abdullahi G. M (2005). Effect of oiling on the proximate composition of Raw Delonixregia seeds. Niger. Food J. 23: 128-132.

[3] Akpati M. I, Miachi O. E (2001). Proximate composition and selected functional properties of Detariummicrocarpum Plant Foods Hum. Nutr. 57 Pp 297-302.

[4] Allen S. E, Grimshaw H. E, Parkison J. A, Quarmby C (1994). Chemical analysis of Ecological Materials. Blackwell Scientific Publications, London. Pp 67-89.

[5] ALR CT94-0981 summary Report 1999 "Cultivation and extraction of Natural Dyes for Industrial use in Natural Textile Production, CPL Press.

[6] Anon (2001) the development and use of natural dyes in textiles. Government of India.

[7] Anwhange B. A, Ajibola V. O, Oniye S. J (2004). Amino acid composition of seeds of Moringaolifera (Lam) Detariummicrocarpum (Guill and Sper) and Bauhinmonandra (Linn). Chem. Class J. Pp 9-13.

[8] Arbonier, M. (2004). Trees, Shrubs and lianas of West African Dry Zone. CIRAD. Magraf Pub., German. Pp. 219 And 220.

[9] Baumer M. (1995). Nutrition and Dietics Health Care $9^{\text {th }}$ edition Chrchill Livingstone, New York. Pp 92-100.

[10] Chadramouli KV (1993) the colour of our lives. PPST Foundation, Chennai, p 79.

[11] Conn E. E (1997) cyanide and cyanogenic glycosides. In: Herbivores: Their interaction with Secondary metabolites. Rosenthal G. A and Janzen, D. H (eds.) Academic press, New York. Pp 387-412.

[12] Dalziel, J. M (1995). The Useful Plants of West Africa Grown Agents for Oversea Grown Agents, London, U.K pp 612.

[13] Devlin T. M (2006). Textbook of Biochemistry with Clinical correlations. $6^{\text {th }}$ edition. John Wiley 7 sons, Inc, Publication. Pp 1094-1116.

[14] Ebi G. C Afieroho O. E (2011). Phytochemical and antimicrobial studies of DeyariummicrocarpumGuill and Sper (Caesalpinioceae) seeds coat. Afr. J. biotechnol. 10 (3): 457462 .

[15] Elemo B. O, Elemo G. N, Oladimeji O. O, Komolafe Y. O (2002). Studies on the composition of some nutrients and antinutrients of sheanut. Niger. Food. J. 20: 69-73.

[16] Eromosele J. N, Eromosele C. O, Akintoye A. O, Komolafe T. O (1994). Characterization of oils and chemical analysis of the seeds of wild plants. Plants foods Hum. Nutr. 46: 361-365.

[17] Hassan M. M, Oyewale A. O, amunian, J. O, Abdullahi M. S, and Okonkwo E. m (2004). Preliminary Phytochemical and Atimicrobial. Investigation of Crude Extract of Root Bark Of Detariummicrocarpum. J. Chem. Sci. Nigeria. 29 (1). 
[18] Hassan (2012), "Aqueous Bark Extract of CinnamomumZeylanicum: A Potential therapeutic agent Forstreptozotocin- Induced Type 1 Diabetes Mellitus (TIDM) Rats", tropical journal of Pharmaceutical Research, 11 (3): Pp 429435.

[19] Irvine, F. R (1961). The Woody Plants of Ghana with Special references to their uses. Oxford university press, London, U.K pp 816.

[20] Kouyate A. M, Van damme P (2006). DetariummicrocarpumGuill and Perr In: Schmelzer, G. Hand Gurib-fakin, A (eds.) Preta 11 (1): Medicinal plants/plantesmedicinates. $1 . \quad$ (CD-Rom) PROTA. Wageningen, Neitherlands.

[21] Linder M. C (1991). Nutritional Biochemistry and Metabolism with Clinical applications. $2^{\text {nd }}$ edition. Apileton and Lange. Pp 215-269.

[22] Malviya N. and Mahajan S (2013). Preliminary Phytochemical Screening of Bark of Some Important Trees of College Campus With Special Reference to Tanim, Glycoside and their Medicinal Properties, International Research Journal of Environment Science. Vol. 2 (11), 13-17 November 2013. Pp 13-16.

[23] Mary C. F (2004), "common tropical plants yield new natral dyes" News Sci. Devinet.
[24] Nwokonkwo D. C, (2013). Synthesis of 2-(1,3-Dihydro-3oxo-2h-pyridylpyrol-2-ylidene)-1,2-Dihydro-3h-pyridylpyrol3-one. IOSR J Appl chem. 4 (6): Pp 74-78.

[25] Onyeyili P. A, Geidam, Y. A. A. G. Ambali, (2007) preliminary phytochemical evaluation of crude Aqueous Extract of Psidiumguajava leaf. Journal of Applied Sciences. 7 (4): pp. 511-514.

[26] padma, S. Vankar N. (2004). Essential oils and Fragrance from Natural Sources, Faculty forEcological and Analytical Testing (FEAT), Indian Institute of Technology. Springer Publishers Kanpur, India. Vol 9 (4) Pp 30-34.

[27] Pereira L, Alves M, (2012). Dyes; Environmental impacts and remediation. In: Malik, A, Grohmann E (eds) Environmental protection strategies for sustainable development, strategies for sustainability. Springer, New York.

[28] Sexena S, Raja A. S. M (2014). Natural Dyes: sources, Chemistry, Application and sustainability Issues. In: Muthu S. (eds) Roadmap to sustainable Textiles and clothing. Textile Scienceand Clothing Technology. Springer, Singapore.

[29] Traubel, H. and Eitel K. (1977), Recent development in leather Dyeing. Bayer Information forLeather Industry pp 6777. 